\title{
Impact of Intrasexual Selection on Sexual Dimorphism and Testes Size in the Mexican Howler Monkeys Alouatta palliata and $A$. pigra
}

\author{
Mary Kelaita, ${ }^{1 *}$ Pedro Américo D. Dias, ${ }^{2}$ Ma. del Socorro Aguilar-Cucurachi, ${ }^{2}$ \\ Domingo Canales-Espinosa, ${ }^{2}$ and Liliana Cortés-Ortiz ${ }^{3}$ \\ ${ }^{1}$ Department of Anthropology, University of Michigan, Ann Arbor, MI 48109-1107 \\ ${ }^{2}$ Instituto de Neuroetología, Universidad Veracruzana, Xalapa, Mexico \\ ${ }^{3}$ Museum of Zoology and Department of Ecology and Evolutionary Biology, University of Michigan, \\ Ann Arbor, MI 48109-1079
}

\section{KEY WORDS body size dimorphism; canine dimorphism; sperm competition}

\begin{abstract}
One of the goals of physical anthropology and primatology is to understand how primate social systems influence the evolution of sexually selected traits. Howler monkeys provide a good model for studying sexual selection due to differences in social systems between related species. Here, we examine data from the sister howler monkey species Alouatta palliata and A. pigra inhabiting southeastern Mexico and northern Guatemala. We use a resampling approach to analyze differences in sexual dimorphism of body and canine size. In addition, we compare testes size as a way of gauging the intensity of sperm competition in both species. Morphometric data were collected from wild-caught individuals, including
\end{abstract}

The theory of sexual selection was proposed to explain the presence of weaponry and/or ornamentation in males in addition to female discrimination of potential reproductive partners (Darwin, 1871). Sexual selection within the sexes, or intrasexual selection, favors traits that allow males to monopolize mating with receptive females, either by preventing rival males from gaining access to females or by maximizing their chances of fertilization (Kappeler and van Schaik, 2004). Larger body size and canine weaponry can confer a fitness advantage to primate males (e.g., mandrills, Leigh et al., 2008). One possible consequence of this advantage is the development of sexual dimorphism (or the difference in form between males and females of the same species). Sexual dimorphism in body mass and canine size is common in primate species (Plavcan and van Schaik, 1997). Presumably, the degree of sexual dimorphism would be greater in species in which males fight with each other for direct access to receptive females than in species that exhibit less male-male competition (Clutton-Brock et al., 1977; Alexander et al., 1979). However, the correlation of the level of sexual dimorphism with the intensity of sexual selection in primates is not always clear, partly due to difficulties in finding appropriate measures to estimate the intensity of sexual selection (Plavcan, 2004), which have included the socionomic sex ratio (CluttonBrock et al., 1977), mating systems (Harvey et al., 1978; Leutenegger and Cheverud, 1985; Lindonfors, 2002), the operational sex ratio (Mitani et al., 1996), and competition levels (Kay et al., 1988; Plavcan and van Schaik, 1992; Ford, 1994). In addition, many comparative analyses suggest that multiple factors (such as mate choice, allometry, phylogenetic constraints, and natural selec- body mass and length, and dental data were obtained from casts from wild individuals and from museum specimens. Although A. pigra individuals are larger than their A. palliata counterparts, we find that both species exhibit similar levels of sexual dimorphism for all of the variables considered. Testicular volume results indicate that $A$. palliata male testes are on average twice as large as those of A. pigra males, suggesting more intense sperm competition in the former species. Our study shows that A. pigra is not highly sexually dimorphic as was once thought, and testes size differences suggest the need for a clearer understanding of howler monkey social systems. Am J Phys Anthropol 146:179-187, 2011. @2011 Wiley-Liss, Inc.

tion to name a few) can influence the expression of sexual dimorphism in primates (reviewed in Plavcan, 2001).

Intrasexual selection can also occur after mating via sperm competition, when multiple males copulate with the same female during a reproductive cycle (Birkhead and Kappeler, 2004). Therefore, male fitness depends not only on the ability to mate with females but also on successful fertilization. It has been demonstrated that in many primate species where females mate with more than one male, males have larger testes in relation to body size than in monogamous or polygynous species (Short, 1979; Harcourt et al., 1981; Harcourt, 1997). For example, in chimpanzees (Pan troglodytes), which live in multimale/multifemale groups, males have large testes on the order of approximately $120 \mathrm{~g}$ of combined weight, whereas the polygynous single-male gorillas (Gorilla gorilla beringei) have testes weighing $30 \mathrm{~g}$ (Dixson and

\footnotetext{
Grant sponsor: NSF; Grant number: DEB-0640519. Grant sponsor: PROMEP UVER; Grant sponsors: Universidad Veracruzana, OVPR at the University of Michigan, Museum of Zoology, Department of Anthropology, Rackham Graduate School at the University of Michigan.

*Correspondence to: Mary Kelaita, Department of Anthropology, 101 West Hall, 1085 S. University Ave. Ann Arbor, Michigan 48109-
} 1107, USA. E-mail: mkelaita@umich.edu

Received 21 July 2010; accepted 25 April 2011

DOI 10.1002/ajpa.21559

Published online 8 August 2011 in Wiley Online Library (wileyonlinelibrary.com). 
Brancoft, 1998). Larger relative testes size accommodates greater sperm production and larger ejaculates (Setchell, 1978; as cited in Kenagy and Trombulak, 1986); hence, individuals with larger testes would in turn increase their chances of fertilization.

Mexican howler monkeys, Alouatta palliata (mantled howler monkey) and A. pigra (Central American black howler monkey), have marked differences in their social systems (Crockett and Eisenberg, 1987; Neville et al., 1988; Treves, 2001) and constitute a good model to explore the differences in sperm competition, as well as how the intensity of intrasexual selection affects sexual dimorphism in closely related species. Having diverged around 3 million years ago (Cortés-Ortiz et al., 2003), A. palliata and A. pigra are sister species that can be clearly distinguished on the basis of genetics (Cortés-Ortiz et al., 2003), cytogenetics (Steinberg et al., 2008), and morphology (Lawrence, 1933; Smith, 1970). Differences in social systems include that $A$. pigra groups usually range from 2 to 12 individuals, with groups averaging 4 to 8 individuals (Crockett and Eisenberg, 1987; Treves, 2001; Chapman and Pavelka, 2005; Van Belle and Estrada, 2006; RosalesMeda et al., 2008). On the other hand, A. palliata typically have groups that are much larger than those of A. pigra, ranging from 2 to 45 individuals and averaging 8 to 23 individuals per group (Crockett and Eisenberg, 1987; Neville et al., 1988; Chapman and Balcomb, 1998; Treves, 2001; Pavelka and Chapman, 2006; Di Fiore and Campbell, 2007). The relative number of females per troop also differs between species: whereas A. palliata troops have a sex ratio between 1.37 and 4.11 females per male, the smaller $A$. pigra troops have a sex ratio between 1.2 and 2.1 females per male (Crockett and Eisenberg, 1987; Neville et al., 1988; Treves, 2001; Van Belle and Estrada, 2006). Females of both species are only receptive during 2-6 days of their approximately 16-day cycle (Glander, 1980; Van Belle et al., 2009), during which males must compete to gain reproductive access. In A. pigra, females copulate most often with the dominant male (Van Belle et al., 2009), whereas in A. palliata copulations with multiple males during a female's estrus cycle are common (Jones and Cortés-Ortiz, 1998; Wang and Milton, 2003).

In both species, males and females migrate from their natal groups and join other groups (Van Belle and Estrada, 2006; Clarke and Glander, 2008). In A. palliata male takeovers usually do not involve the ousting of resident males (Glander, 1980), but instead are a way to attain group membership by the invader male (Dias et al., 2010). Although nonalpha $A$. palliata males may face decreased possibilities of monopolizing a receptive female, they can still achieve reproduction through alternative strategies (Jones, 1985; Cortés-Ortiz, 1998; Jones and Cortés-Ortiz, 1998). Small, low-ranking males in these groups would still have an opportunity to reproduce by being able to sneak in copulations and pass on their characteristics to their offspring (i.e., not only large males will sire offspring). Furthermore, a larger number of females in the group implies a higher probability that two or more will be in estrus simultaneously, facilitating the access of multiple males to receptive females (Dunbar, 1988). In contrast, A. pigra males are often expelled from the group during a takeover (Brockett et al., 2000). As groups usually have one or two males, the invader male may actually be able to force out all resident males. However, it has been suggested that males in $A$. pigra groups are kin-related and cooperate in the defense of the group (Kitchen, 2004). Therefore, it would be harder for an invader male to defeat a coalition of two or more related resident males. Only large males (and presumably those with large canines that can be useful during battle) would be able to successfully defeat a coalition of resident males, and so it would be expected that large body size and canines would be selected for by being preferentially passed on to the next generation.

In this study, we analyze sexual dimorphism and testes size for the two species of Mexican howler monkeys and explore the connection of these variables with malemale and sperm competition. While sexual dimorphism has been investigated via broad comparative analyses, a closer look at these two related species with different social systems can help to parse out some of the determinants of sexual dimorphism, at least in platyrrhines. Given the complexity of the social dynamics of these species (presented above), it is difficult to establish straightforward predictions in terms of the expression of sexual dimorphism for each species. The socionomic sex ratio alone suggests that $A$. palliata has more intense malemale competition and reproductive skew than A. pigra. This would imply that $A$. palliata should be more sexually dimorphic than A. pigra. Yet, since A. palliata groups are large and males may have difficulty monopolizing females, reproductive skew may be lower in this species than in $A$. pigra. Furthermore, although many $A$. pigra groups are unimale, the sex ratio is generally low, and the suggestion that group males are related could mean lower intragroup male-male competition. However, kinship of males in the group and the formation of coalitions may intensify intergroup male-male competition for group takeover. These issues, in addition to the role played by female choice and competition, complicate inferences that can be made about sexual dimorphism in body and canine size.

Alouatta pigra has been reported to be more sexually dimorphic in body size than A. palliata (Jungers, 1985; Ford and Davis, 1992; Ford, 1994). However, previous analyses are based on a very small sample size (only two males) for A. pigra, so it remains unclear whether a larger sample size supports this difference. Canine data is available for both A. palliata and A. pigra (Swindler, 2002; Plavcan and Ruff, 2008) although not specifically for A. palliata mexicana. Testes size (only in terms of mass, not volume) has only been reported for A. palliata (Harcourt et al., 1981). With greater sampling of body mass data and newly acquired testicular volume and dental data from wild-caught individuals of both species, in this study we examine how body and canine size dimorphism and testicular volume vary between the two species, and discuss how the observed patterns may have been shaped by differences in social systems between $A$. pigra and A. palliata.

\section{METHODS Data collection}

Between 1998 and 2008, we collected morphometric measurements, dental molds, and blood samples of howler monkeys from southeastern Mexico (A. palliata and A. pigra) and Northern Guatemala (A. pigra). We followed capturing procedures described in RodríguezLuna and Cortés-Ortiz (1994). Sample sizes for the collected data are shown in Table 1.

Although $A$. pigra and $A$. palliata are known to naturally hybridize in Mexico (Cortés-Ortiz et al., 2007), individuals in this study are all considered to be purebred. Both pure A. palliata and A. pigra individuals were col- 
TABLE 1. Sample size (N), mean, standard deviation (SD), and ranges for A. pigra and A. palliata morphological variables for both sexes and results of testing for significance of the differences between the two species ( $P$ value)

\begin{tabular}{|c|c|c|c|c|c|c|c|c|c|}
\hline & \multicolumn{4}{|c|}{ A. pigra } & \multicolumn{4}{|c|}{ A. palliata } & \multirow[b]{2}{*}{$P$ value } \\
\hline & $N$ & Mean & SD & Range & $N$ & Mean & SD & Range & \\
\hline \multicolumn{10}{|l|}{ Body mass (kg) } \\
\hline Female & 32 & 5.68 & 0.63 & $4.50-6.8$ & 37 & 4.39 & 0.48 & $3.60-5.25$ & $<0.001$ \\
\hline Male & 37 & 7.60 & 1.13 & $5.50-9.60$ & 25 & 5.80 & 0.69 & $4.60-7.20$ & $<0.001$ \\
\hline \multicolumn{10}{|l|}{ Sitting height (cm) } \\
\hline Female & 32 & 43.5 & 2.9 & $34.5-49.0$ & 36 & 38.8 & 2.4 & $33.0-43.7$ & $<0.001$ \\
\hline Male & 37 & 48.5 & 3.2 & $42.6-58.0$ & 26 & 41.0 & 2.3 & $37.0-45.4$ & $<0.001$ \\
\hline Testicular volume $\left(\mathrm{cm}^{3}\right)$ & 36 & 11.33 & 3.79 & $5.06-18.95$ & 24 & 22.66 & 10.89 & $11.39-61.22$ & $<0.001$ \\
\hline \multicolumn{10}{|l|}{ Canine height $(\mathrm{mm})$} \\
\hline Female & 18 & 8.88 & 1.39 & $7.12-11.63$ & 23 & 8.14 & 1.06 & $6.65-10.06$ & 0.083 \\
\hline Male & 20 & 14.23 & 2.00 & $9.00-17.00$ & 19 & 14.01 & 1.75 & $11.29-17.75$ & 0.509 \\
\hline \multicolumn{10}{|c|}{ Canine mesiodistal length (mm) } \\
\hline Female & 9 & 6.72 & 0.43 & $6.06-7.35$ & 15 & 6.15 & 0.49 & $5.12-7.18$ & 0.006 \\
\hline Male & 10 & 8.29 & 0.76 & $7.48-9.53$ & 10 & 8.08 & 0.63 & $7.00-8.93$ & 0.597 \\
\hline \multicolumn{10}{|c|}{ Canine labiolingual length (mm) } \\
\hline Female & 8 & 5.11 & 0.39 & $4.81-5.92$ & 13 & 4.76 & 0.36 & $4.25-5.62$ & 0.060 \\
\hline Male & 9 & 6.57 & 0.75 & $5.64-7.62$ & 10 & 6.81 & 0.97 & $5.44-8.65$ & 0.744 \\
\hline
\end{tabular}

lected outside the known hybrid zone in Tabasco (CortésOrtiz et al., 2007). We also included individuals from within the hybrid zone after confirming parental species status using 11 microsatellite markers, five of which are diagnostic of hybridization (Cortés-Ortiz et al., 2009). Procedures for capturing and handling primates were approved by the University Committee on Use and Care of Animals (UCUCA) at the University of Michigan.

We used only adults in this study. As we did not track these individuals from birth, we could not ascertain the exact age and had to rely on other proxies to determine adult status. For both species, we followed dental development and wear patterns of captured individuals according to the criteria developed in Pope (1966), and we assigned adult status for individuals with fully-erupted dentition and the third molar in functional occlusion, and at least slight wear found on some of the premolars and first molar. Howler monkeys are known to have reached sexual maturity at that stage (DeGusta and Milton, 1998), and although most craniometric studies only use the criterion that all teeth are erupted to determine adult status (Ravosa and Ross, 1994; Jones et al., 2000), we believe that our criteria is more stringent by including all sexually mature individuals.

Morphometrics. Once animals were captured, mass measurements were collected using a $20-\mathrm{kg}$ Pesola ${ }^{\mathbb{B}}$ spring scale to the nearest $100 \mathrm{~g}$. Body mass is commonly used as a marker of overall body size in living primates (e.g., Ford and Davis, 1992). Here we used body mass and a linear body length measurement to estimate sexual size dimorphism in the two species. Mass data for A. palliata from different sites throughout their geographic distribution have been reported extensively (17 studies and $N>459$ individuals: Ford and Davis, 1992; Glander, 2006), but data for A. pigra are scarce. Most studies that use body mass data for $A$. pigra relied on the data presented by Murie (1935) and Jungers (1985), with a sample size of two males and three females. Our larger A. pigra sample provides a more accurate representation of average $A$. pigra body mass ( 32 females and 37 males).

The body length measurement analyzed in this study is the sitting height (i.e., the length of the head and body excluding the tail, similar to the measurement used by Schultz, 1929). This measurement was taken dorsally from the junction of the last lumbar and first caudal vertebrae to the occipital protuberance of the head using a metallic measuring tape to the nearest 0.1 $\mathrm{cm}$. Body length measurements are sometimes favored over body mass measurements because they are less subject to variation caused by nutritional and health status (Alexander et al., 1979). We use both measurements in this study to account for possible biases due to such factors.

Dental casting. While the animal was anesthetized, negative dental impressions were made using vinyl polysiloxane material (Exaflex ${ }^{\mathrm{TM}}$ Putty, GC America, Alsip, IL). Casts were poured using polyester laminating resin thickened with talc and catalyzed with methyl-ethyl-ketone (Eastpointe Fiberglass Sales, Eastpointe, MI). A paired $t$-test was used to compare upper canine height measurements performed in the field with measurements taken from the casts of the same individuals $(N=$ $50)$. Results of these tests revealed no significant differences $(t=-0.491, P=0.626)$, indicating that our casts were representative of live specimens. All measurements were made with Mitutoyo ${ }^{\mathbb{R}}$ Digital Calipers to the nearest $0.01 \mathrm{~cm}$.

Canine measurement. We measured upper canine height, mesiodistal length, and labiolingual (also known as buccolingual) length from dental casts. Our own field observations suggest that upper canine height is highly susceptible to wear, and some wear was observed in the mesiodistal dimension as well. However, considering that wear is a continuous process and begins to occur prior to complete eruption of the tooth, we decided to include these data and consider this source of error in our analysis, excluding any teeth that were heavily worn. Our measurement of upper canine height is taken from the apex to the buccal-gingival margin, which is slightly above the cementum-enamel junction due to the presence of the gum in live-captured individuals. The mesiodistal and labiolingual dimensions are measured as described in Plavcan and van Schaik (1992) but are not exactly analogous to those measurements due to the presence of gum tissue in wild-captured individuals. We also included museum dental specimens housed at the University of Michigan Museum of Zoology mammal col- 
lection $(N=9)$. Only Mexican A. palliata museum samples were included, and all $A$. pigra museum samples (which include those individuals analyzed by Murie, 1935) came from Petén, Guatemala. In the casts of live animals, measurements for upper canine base dimensions were made at the gum line. Museum specimens retained stains on the canines that indicate the location of the gum line when the animals were alive, making it possible to perform analogous measurements in live and museum specimens. We measured left maxillary canines, and in cases where the tooth was broken we used the right maxillary canine $(N=2)$.

Testicular volume. To determine testicular volume, we measured testicular breadth and length to the nearest millimeter using Mitutoyo ${ }^{\circledR}$ Digital Calipers, excluding scrotal skin folds. We used the following formula for calculating the volume of a prolate sphere: $\pi L W^{2} / 6$; where $L$ is length and $W$ is width (Harrison et al., 1977). We utilized total testicular volume (sum of left and right testes) to account for any variability that exists between the left and right testes and to have data that are comparable to results presented in the literature. Comparison of testes size across species often involves relating absolute testicular volume with body mass (Short, 1979; Harcourt et al., 1981); here we only present absolute testicular volume, but using relative volume did not affect our results.

\section{Statistical analyses}

We used the Shapiro-Wilk test of normality and found that of 22 sample groups, all were normally-distributed except for 4: A. palliata male sitting height and A. pigra female body mass, sitting height, and canine labiolingual length. For that reason and since some sample sizes are small, we used the Mann-Whitney nonparametric test to determine whether there were significant differences between the sexes (except for testicular volume) and between the species.

To quantify sexual dimorphism, we used the intuitive ratio of average male to female values, which is widely used since the larger sex is preferred in the numerator (Smith, 1999). Because sample sizes and variances are unequal and because some of the variables are not normally distributed, we utilized a resampling method to avoid making assumptions about how the data were distributed (Lee, 1999). We pooled males of the two species in one group and females in the other. We randomly selected and averaged a group of males based on the male sample size of one species and divided that value by the average of a randomly selected group of females based on the female sample size of the same species to obtain a value of sexual dimorphism. We repeated this procedure to obtain a random value of sexual dimorphism for the second species, and then subtracted the dimorphism values of the two species from one another. This process was repeated 10,000 times to generate a distribution of randomly sampled sexual dimorphism differences. Then, we tested the null hypothesis that our test statistic, which is the difference between the actual sexual dimorphism values of $A$. palliata and A. pigra, fell within the $95 \%$ confidence interval (alpha value of 0.025 for a two-tailed test). Statistical analyses were done using SPSS 16.0 and the Resampling Statistics Excel macro.
TABLE 2. Dimorphism values (mean male/mean female) for A. pigra and A. palliata, and results of testing for significance of differences in dimorphism using resampling

\begin{tabular}{lccc}
\hline & A. pigra & A. palliata & $P$ value $^{\mathrm{a}}$ \\
\hline Body mass dimorphism & 1.34 & 1.31 & 0.431 \\
Sitting height dimorphism & 1.12 & 1.06 & 0.053 \\
Canine height & 1.60 & 1.72 & 0.127 \\
Canine mesiodistal length & 1.23 & 1.31 & 0.113 \\
Canine labiolingual length & 1.29 & 1.43 & 0.059 \\
\hline
\end{tabular}

${ }^{\text {a }} P$ value represents the significance value generated using resampling statistics.

\section{RESULTS}

Table 1 shows the descriptive statistics for body mass, sitting height, canine dimensions, and testicular volume for both species. Table 1 also shows results for significance testing of all variables for differences between the species for each sex. Males are significantly larger than females for all variables $(P<0.001)$. Both male and female $A$. pigra individuals are heavier in body mass and larger in sitting height than their A. palliata counterparts. Interestingly, male upper canine dimensions are not significantly different between the two species but female canine mesiodistal length is, and other female dimensions approach significance.

Although $A$. pigra males are the larger of the two, $A$. palliata males have testes that are twice as large as their A. pigra counterparts. The difference in absolute testicular volume is great enough that correcting for the effects of body size has no bearing on our results and only serves to increase the difference in the relative testicular volume between the two species.

Table 2 shows the sexual dimorphism values for body mass, sitting height, and upper canine dimensions, and the significance values from the resampling test. Upper canines exhibit greater dimorphism than body mass (while canine dimensions are linear, body mass is volumetric, so taking the cube root gives values of 1.10 and 1.09 for A. pigra and A. palliata respectively). Nevertheless, neither body mass, sitting height, nor canine dimensions showed any significant differences in sexual dimorphism between the species.

\section{DISCUSSION}

Our results show that overall $A$. pigra males and females are bigger than their A. palliata counterparts, but have similar upper canine size, and that both species exhibit sexual dimorphism in body mass, sitting height, and upper canine size. Our data for A. palliata mexicana fall within the ranges in mass reported by other authors for A. palliata palliata inhabiting Costa Rica (Ford and Davis, 1992; Glander, 2006), but not for A. palliata aequatorialis in Barro Colorado Island, Panama (Scott et al., 1977; Glander, 2006). On the other hand, A. pigra average male body mass has been overestimated (11.352 kg: Ford and Davis, 1992), probably because most studies for A. pigra relied on the data presented by Murie (1935) and Jungers (1985) using males on the largest end of their size range. Because of the overestimation in male size in previous studies, $A$. pigra has been found to be highly sexually dimorphic (1.764: Ford and Davis, 1992). However, in our study the degree of sexual dimorphism for all three variables does not differ between $A$. palliata and A. pigra. On the other hand, the evidence 
that $A$. palliata testes are much larger than those of $A$. pigra supports the argument that there is more intense post-copulatory competition in A. palliata.

\section{Sexual dimorphism}

In most anthropoid primates, males are larger than females (Plavcan, 2001). Although platyrrhines on the whole have been characterized by lesser degrees of body mass dimorphism, some authors claim that $A$. pigra is the exception, with body mass dimorphism comparable to cercopithecoid species (Ford, 1994). Our new data do not support that view, and instead place $A$. pigra within similar body mass and length dimorphism ranges as other New World primates with high levels of male-male competition (e.g., Saimiri and Cebus species), and more specifically, similar to some other howler monkey species (Alexander et al., 1979; Kay et al., 1988; Ford, 1994; Plavcan and Ruff, 2008).

Like in body mass and length, we found that both species exhibit sexual dimorphism in upper canine size. When used as a weapon, a canine is most effective with respect to its height (Greenfield and Washburn, 1992; Plavcan, 1993). While some argue that, in addition to canine height, the basal dimensions are also good indicators of competition (Lucas et al., 1986), others have found them to be weakly correlated with behavioral measures (Plavcan, 2000). While we present upper canine data for A. palliata mexicana, and although our measurements on teeth of live-captured animals are not necessarily comparable to measurements normally conducted on museum specimens (see methods), all dimensions seem to be similar to other A. palliata reported values (Swindler, 2002; Plavcan and Ruff, 2008). Our sexual dimorphism values are slightly higher for $A$. palliata labiolingual length primarily because we observed larger male measurements. Our A. pigra values are higher than those reported by Swindler (2002; summarized in Plavcan and Ruff, 2008) of 1.1 for canine mesiodistal length, 1.12 for canine height, and 1.11 for canine labiolingual length, but are in agreement with values reported in Plavcan and van Schaik (listed as A. villosa, 1992). All these values fall within the range of canine sexual dimorphism values for many New World monkeys such as Ateles, Lagothrix, and other Alouatta species, but are not as high as those of many Old World monkeys like Macaca or Papio (Plavcan, 2001; Thorén et al., 2006).

Sexual size dimorphism in anthropoids is generally associated with male reproductive skew depending primarily on precopulatory competition, in which selection leads to increased male weaponry (e.g., large canines: Plavcan and Kay, 1988; Kay et al., 1988; Plavcan, 2001) and competitive ability (e.g., large body size: Ford, 1994; Mitani et al., 1996; Plavcan and van Schaik, 1997; Plavcan, 2001). The fact that both $A$. palliata and A. pigra are dimorphic in both upper canine teeth and body size fits well with the concept that sexual selection has favored these traits because of the advantages they confer in winning fights (Plavcan, 2001). Indeed, there is evidence in both species for aggressive encounters among males that lead to fights, injuries and death (DeGusta and Milton, 1998; Cristóbal-Azkarate et al., 2004; Van Belle et al., 2008; Dias et al., 2010). Body mass dimorphism for these two species appears to be similar to those reported for other howler monkeys (see Ford and Davis, 1992; Plavcan and Ruff, 2008). However, upper canine dimorphism data is more variable across the genus (Plavcan and Ruff, 2008), although given methodological differences with other studies and without significance testing, the apparent differences in dimorphism values may not reflect real differences among all the species.

For all of the measures of sexual dimorphism considered in this study, we found no statistically significant differences between the two species, despite the differences between the species in the availability of receptive females over space and time and the differences in male and female mating strategies. Females of A. palliata will not only mate with the dominant, and presumably largest, male but may also mate with smaller males, when the dominant male is unable to monopolize access to all receptive females (Cortés-Ortiz, 1998). However, A. palliata sexual dimorphism is not reduced in comparison with $A$. pigra despite that whenever females copulate with more than one male, sexual dimorphism is typically reduced (Harvey and Harcourt, 1984; Dunbar and Cowlishaw, 1992; Plavcan, 2001). Perhaps greater sexual dimorphism that is otherwise expected in A. pigra (since one male is more likely to monopolize reproduction) is tempered by his relatedness to the other group males. While the lack of differences in sexual dimorphism between $A$. palliata and A. pigra may result from a similarity in the intensity of male-male competition in the two species, other determinants could also affect male and female body and canine size independently. Phylogenetic factors, especially considering the similarities in body mass sexual dimorphism of the species considered in this study with other howler monkeys (possibly with the exception of $A$. caraya), could restrict changes in sexual dimorphism (Cheverud et al., 1985; Plavcan, 2001). Female-female competition and female choice are also likely to contribute to sexual dimorphism in these howler monkeys.

Female-female competition may increase female body and canine size, leading to smaller differences between males and females (Plavcan and van Schaik, 1992). Howler monkey females may compete against one another not only for resources, but also to avoid infanticide risk (Ostro et al., 2001). Large groups with many females are good candidates for male takeover (Crockett, 2003), so it would be in a female's interest to keep group size down by evicting other females (Pope, 2000). This would limit the selection on males for larger body and canine size, and would also result in selection on females for those traits (Plavcan, 2001), as the ability of natal females to compete against immigrating females and expelling nonrelated females from their group may also depend on the development of weaponry and larger body size. In A. pigra, where extra-group male takeovers are common and sometimes result in infanticide (Brockett et al., 1999; Horwich et al., 2001), females may choose to limit group size by engaging in aggressive encounters, much like in red howler monkeys (Crockett, 1984). Male takeover, infanticide, and female emigration also occur in A. palliata (Clarke and Glander, 1984; Crockett and Eisenberg, 1987; Glander, 1992). However, when many males exist in a large group, one male is unable to monopolize all females, and females may develop less costly strategies to confound paternity and lower risk for infanticide (Crockett and Janson, 2000, see female choice below). The $A$. pigra female canine mesiodistal length is significantly larger than that of A. palliata females. Relative canine size of males and females, and not only sex- 
ual dimorphism, can be informative on the levels of intrasexual competition (Plavcan, 2004). Therefore, whereas the similarity in sexual size dimorphism between the two species could mean that both have the same intensity of precopulatory male-male competition, the facts that both male and female $A$. pigra individuals are larger in body size than their A. palliata counterparts, and females have larger canines, suggest the alternative possibility that for both sexes, competition is greater in A. pigra than it is in A. palliata.

Female choice may also play a role in shaping sexual dimorphism (Plavcan, 2004). On the one hand, females may choose to confound paternity by mating with multiple males as a strategy to counteract infanticide (Plavcan, 2001). A. palliata females are known to copulate with several males in their group (Cortés-Ortiz, 1998; Jones and Cortés-Ortiz, 1998; Wang and Milton, 2003) and $A$. pigra females sometimes cross the boundaries of their own group and mate with extragroup males (Horwich, 1983, 2000; Van Belle et al., 2009). On the other hand, females may choose to associate with specific males that they select to sire their offspring and protect them (Plavcan, 2001). Van Belle et al. (2009) present evidence that $A$. pigra females direct many of their sexual solicitations specifically towards dominant males. Therefore, female choice is likely to be an important factor in the evolution of sexual dimorphism in howler monkeys.

Additional studies of howler monkey social behavior and genetic data on paternity are needed to further elucidate the correlates of sexual dimorphism in these species. Nevertheless, our knowledge of these howler monkeys' social systems suggests that both male and female reproductive strategies can influence the degree of sexual dimorphism in A. palliata and A. pigra, and that sexual dimorphism is not necessarily a unique function of male-male competition. Furthermore, these results highlight the complexity of primate social dynamics and the difficulty of drawing simple predictions about the levels of sexual dimorphism based on behavior, warning those researchers that make inferences about behavior from sexual dimorphism data of fossil taxa.

\section{Testicular volume}

Consistent with the prediction that testes size is larger in species with multimale groups, A. palliata males have larger testes than $A$. pigra males. In fact, the volume of A. palliata testes was twice as large as those of $A$. pigra. As these howler monkey species are nonseasonal breeders (Neville et al., 1988), we can assume that there is no seasonal variation in testicular volume (Muehlenbein et al., 2002) and that differences in testes size reflect differences in the intensity of sperm competition (Birkhead and Kappeler, 2004). Thus, sperm competition appears to be more intense in A. palliata.

Compared with other anthropoids, the A. palliata gonadosomatic index (testicular volume relative to body size) fits within the ranges documented for large group multimale/multifemale breeding systems, such as savanna baboons (Bercovitch, 1989), though it is not as large as many macaque species, which are known to have the highest levels of sperm competition (Harcourt et al., 1981). The gonadosomatic index of A. pigra, on the other hand, is slightly higher than those single male/ polygynous species such as gorillas, orangutans, colobus monkeys or hamadrayas baboons (Harcourt et al., 1981). Another howler monkey species, A. caraya, exhibits a combined testicular volume of approximately $16 \mathrm{~cm}^{3}$ (Moreland et al., 2001) and lives in groups that typically have 5-15 individuals (i.e., slightly larger than in $A$. pigra), which can be both unimale and multimale (Juárez et al., 2005). Compared with our measurements of $11 \mathrm{~cm}^{3}$ and $22 \mathrm{~cm}^{3}$ for $A$. pigra and A. palliata, respectively, these differences suggest more sperm competition in $A$. caraya than in $A$. pigra, but perhaps not as much as in A. palliata.

Early studies characterized A. palliata as predominantly polygynous with one dominant male monopolizing breeding opportunities with all the females in the troop (Clarke, 1983), and subordinate males copulating with females outside of the peak of the estrus cycle (Jones, 1985). However, the difference in testicular volume suggests that subordinate A. palliata males are sometimes successful at fertilizing receptive females. As noted earlier, A. palliata groups are large, and there can be up to six males and nine females in a group (Treves, 2001). In larger groups, it is statistically reasonable to assume that many females will be in reproductive synchrony (Dunbar, 1988), and a male must guard all of them against solicitations from other males. Thus, it may not be possible for one male to control access to all females in estrus. Observations from Mexico (Cortés-Ortiz, 1998; Jones and Cortés-Ortiz, 1998), Costa Rica (Jones, 1978) and Panama (Wang and Milton, 2003) indicate that $A$. palliata females may repeatedly copulate with different males during the same estrus cycle. As opposed to engaging in aggressive combat with the dominant male, subordinate males may instead benefit by sneaking in copulations (Harcourt, 1996). Sneaking males may copulate with a receptive female while the guarding male is momentarily away from the female, eating or chasing away other males (Cortés-Ortiz, 1998). Therefore, the high levels of sperm competition and the strong selection for larger testes observed in our data for A. palliata are consistent with our expectations based on what is known about the sociosexual behavior of this species.

As we mentioned earlier for A. pigra, females copulating with males of neighboring groups have been recorded (Horwich, 1983; 2000) but selection for larger testes would be weak if the dominant male succeeds at fertilizing most receptive females, as suggested by recent studies (Van Belle et al., 2009). In the red howler monkey, $A$. seniculus, where subordinate males may copulate with receptive females (Sekulic, 1983), paternity analysis showed that in nine different troops, only the dominant male sired all the offspring (Pope, 1990). To determine the extent of reproductive success and skew among $A$. pigra and A. palliata males, it is imperative to conduct long-term behavioral and genetic studies.

The results presented in this study provide strong evidence that corrects the misconception that A. pigra is more dimorphic than any other New World primate and sets up new hypotheses to be tested to understand the social systems of howler monkeys.

\section{ACKNOWLEDGMENTS}

We thank Milford Wolpoff, John Mitani, and Laura MacLatchy for advice and feedback on research methods and initial drafts of this manuscript and Tom Duda, Jr. for his help with resampling analyses. Also, we thank William J. Sanders for his contributions to and advice on the dental component of this study, and for allowing us to perform dental casting in his lab at the University of 
Michigan Museum of Paleontology. This study was made possible for L. Cortés-Ortiz by PROMEP UVER, Universidad Veracruzana, OVPR at the University of Michigan, and NSF DEB-0640519. Special thanks to our Mexican collaborators Francisco García and Javier Hermida, as well as to Paulo Quintana, Ariadna Rangel, María de Jesús Rovirosa, Alba Rodas, Alejandro Coyohua, and Thore Bergman for fieldwork assistance. Genetic work to confirm the pure-species status of individuals was conducted at the Genomic Diversity Laboratory of the Museum of Zoology, University of Michigan. Official permits to collect data presented in this research were obtained from SEMARNAT, Mexico (permits SGPA/DGVS/03676/07, SGPA/DGVS/06116, SGPA/DGVS/03042， DOO.02-0789, DOO 750.-10070/98).

\section{LITERATURE CITED}

Alexander RD, Hoogland JL, Howard RD, Noonan KM, Sherman PW. 1979. Sexual dimorphism and breeding systems in pinnipeds, ungulates, primates and humans. In: Chagnon NA, Irons W, editors. Evolutionary biology and human social behavior: an anthropological perspective. North Scituate, MA: Duxbury Press. p 402-435.

Bercovitch F. 1989. Body size, sperm competition, and determinants of reproductive success in male savanna baboons. Evolution 43:1507-1521.

Birkhead TR, Kappeler PM. 2004. Post-copulatory sexual selection in birds and primates. In: Kappeler PM, van Schaik CP, editors. Sexual selection in primates: new and comparative perspectives. Cambridge: Cambridge University Press. p 151171.

Brockett RC, Horwich RH, Jones CB. 2000. Female dispersal in the Belizean black howling monkey (Alouatta pigra). Neotrop Primates 8:32-34.

Brockett RC, Horwich RH, Jones CB. 1999. Disappearance of infants following male takeovers in the Belizean black howler monkey (Alouatta pigra). Neotrop Primates 7:86-88.

Chapman CA, Balcomb SR. 1998. Population characteristics of howlers: ecological conditions or group history. Int J Primatol 19:385-403.

Chapman CA, Pavelka MSM. 2005. Group size in folivorous primates: ecological constraints and the possible influence of social factors. Primates 46:1-9.

Cheverud JM, Dow MM, Leutenegger W. 1985. The quantitative assessment of phylogenetic constraints in comparative analysis: sexual dimorphism in body weight among primates. Evolution 38:1335-1351.

Clarke MR. 1983. Infant-killing and infant disappearance following male takeovers in a group of free-ranging howling monkeys (Alouatta palliata) in Costa Rica. Am J Primatol 5:241-247.

Clarke MR, Glander KE. 1984. Female reproductive success in a group of free-ranging howling monkeys (Alouatta palliata) in Costa Rica. In: Small M, editor. Female primates: studies by women primatologists. New York: Alan R. Liss. p 111-126.

Clarke MR, Glander KE. 2008. Natal emigration by both sexes in the La Pacifica population of mantled howlers: when do some stay? Am J Primatol 70:195-200.

Clutton-Brock TH. 1985. Size, sexual dimorphism, and polygyny in primates. In: Jungers WL, editor. Size and scaling in primate biology. New York: Plenum Press. p 51-60.

Clutton-Brock TH, Harvey PH, Rudder B. 1977. Sexual dimorphism, socionomic sex ratio and body weight in primates. Nature 269:797-800

Cortés-Ortiz L. 1998. Sistema de apareamiento y comportamiento sexual del mono aullador Alouatta palliata mexicana en Semilibertad. M. Sc. thesis, Universidad Veracruzana, Xalapa, Veracruz.

Cortés-Ortiz L, Bermingham E, Rico C, Rodríguez-Luna E, Sampaio I, Ruiz-García M. 2003. Molecular systematics and bio- geography of the Neotropical monkey genus, Alouatta. Mol Phylogenet Evol 26:64-81.

Cortés-Ortiz L, Duda TF, Jr, Canales-Espinosa D, GarcíaOrduña F, Rodríguez-Luna E, Bermingham E. 2007. Hybridization in large-bodied New World primates. Genetics 176: 2421-2425.

Cortés-Ortiz L, Mondragón E, Cabotage J. 2009. Isolation and characterization of microsatellite loci for the study of Mexican howler monkeys, their natural hybrids, and other Neotropical primates. Conservation Genet Resour. DOI 10.1007/s12686009-9124-6. Published online on October 30:2009.

Cristóbal-Azkarate J, Dias PAD, Veà JJ. 2004. Causes of intraspecific aggression in Alouatta palliata mexicana: evidence from injuries, demography, and habitat. Int J Primatol 25:939-953.

Crockett CM. 1984. Emigration by female red howler monkeys and the case for female competition. In: Small MF, editor Female primates: studies by women primatologists. New York: Alan R. Liss. p 159-173.

Crockett CM. 2003. Re-evaluating the sexual selection hypothesis for infanticide by Alouatta males. In: Jones CB, editor. Sexual selection and reproductive competition in primates: new perspectives and directions. Norman, OK: American Society of Primatologists. p 327-365.

Crockett CM, Eisenberg JF. 1987. Howlers: variations in group size and demography. In: Smuts BB, Cheney DL, Seyfarth RM, Wrangham RW, Struhsaker TT, editors. Primate societies. Chicago: University of Chicago Press. p 54-68.

Crockett CM, Janson CH. 2000. Infanticide in red howlers: female group size, male composition, and a possible link to folivory. In: van Schaik CP, Janson $\mathrm{CH}$, editors. Infanticide by males and its implications. Cambridge: Cambridge University Press. p 75-98.

Darwin C. 1871. The descent of man and selection in relation to sex. London: Murray.

DeGusta D, Milton K. 1998. Skeletal pathologies in a population of Alouatta palliata: behavioral, ecological, and evolutionary implications. Int J Primatol 19:615-650.

Dias PAD, Rangel-Negrin A, Veá JJ, Canales-Espinosa D. 2010. Coalitions and male-male behavior in Alouatta palliata. Primates 51:91-94.

Dixson AF, Brancoft J. 1998. Primate sexuality: comparative studies of the prosimians, monkeys, apes, and human beings. Oxford: Oxford University Press. p 219.

Di Fiore A, Campbell CJ. 2007. The atelines: variation in ecology, behavior, and social organization. In: Campbell CJ, Fuentes A, MacKinnon KC, Panger M, Bearder SK, editors. Primates in perspective. New York: Oxford University Press. p 155-185.

Dunbar RIM. 1988. Primate social systems. London: Croom Helm.

Dunbar RIM, Cowlishaw G. 1992. Mating success in male primates: dominance rank, sperm competition and alternative strategies. Anim Behav 44:1171-1173.

Ford SM, Davis LC. 1992. Systematics and body size: implications for feeding adaptations in New World monkeys. Am J Phys Anthropol 88:415-468.

Ford SM. 1994. Evolution of sexual dimorphism in body weight in platyrrhines. Am J Primatol 34:221-244.

Glander KE. 1980. Reproduction and population growth in freeranging mantled howling monkeys. Am J Phys Anthropol 53:25-36.

Glander KE. 1992. Dispersal patterns in Costa Rican mantled howling monkeys. Int J Primatol 13:415-436.

Glander KE. 2006. Average body weight for mantled howling monkeys (Alouatta palliata): an assessment of average values and variability. In: Estrada A, Garber PA, Pavelka MSM, Luecke LG, editors. New perspectives in the study of Mesoamerican primates: distribution, ecology, and conservation. New York: Springer. p 247-263.

Greenfield LO, Washburn A. 1992. Polymorphic aspects of male anthropoid canines. Am J Phys Anthropol 84:17-34.

Harcourt AH, Harvey PH, Larson SG, Short RV. 1981. Testis weight, body weight, and breeding system in primates. Nature 291:55-57. 
Harcourt AH. 1996. Sexual selection and sperm competition in primates: what are male genitalia good for? Evol Anthropol 4:121-129.

Harcourt AH. 1997. Sperm competition in primates. Am Nat 149:189-194.

Harrison RM, Dominguez GJ, Heidger PM, Roberts JA, Schlegel JV. 1977. Vasectomy in rhesus monkeys. I. Surgical techniques and gross observations. Urology 9:639-644.

Harvey PH, Harcourt AH. 1984. Sperm competition, testes size, and breeding systems in primates. In: Smith RL, editor. Sperm competition and the evolution of animal mating systems. New York: Academic Press. p 589-600.

Harvey PH, Kavanagh M, Clutton-Brock TH. 1978. Sexual dimorphism in primate teeth. J Zool Lond 186:475-485.

Horwich RH. 1983. Breeding behaviors in the black howler monkey (Alouatta pigra) of Belize. Primates 24:222-230.

Horwich RH. 2000. Alternative male reproductive behaviors in the Belizean black howler monkey (Alouatta pigra). Neotrop Primates 8:95-98.

Horwich RH, Brockett RC, James RA, Jones CB. 2001. Population structure and group productivity of the Belizean black howling monkey (Alouatta pigra): implications for female socioecology. Primate Rep 61:47-65.

Jones AL, Degusta D, Turner SP, Campbell CJ, Milton K. 2000. Craniometric variation in a population of mantled howler monkeys (Alouatta palliata): evidence of size selection in females and growth in dentally mature males. Am J Phys Anthropol 113:411-434.

Jones CB. 1978. Aspects of reproduction in the mantled howler monkey (AIouatta palliata GRAY). Ph.D. Dissertation, Ithaca: Cornell University.

Jones CB. 1985. Reproductive patterns in mantled howler monkeys: estrus, mate choice and copulation. Primates 26:130142.

Jones CB, Cortés-Ortiz L. 1998. Facultative polyandry in the howling monkey (Alouatta palliata): Carpenter was correct. Boletín Primatológico Latinoamericano 7:1-7.

Juárez CP, Dvoskin R, Fernández-Duque E. 2005. Structure and composition of wild black howler troops (Alouatta caraya) in gallery forests of the Argentinean Chaco. Neotrop Primates 13:19-22.

Jungers WL. 1985. Body size and scaling of limb properties in primates. In: Jungers WL, editor. Size and scaling in primate biology. New York: Plenum Press. p 345-381.

Kappeler PM, van Schaik CP. 2004. Sexual selection in primates: review and selection preview. In: Kappeler PM, van Schaik CP, editors. Sexual selection in primates: new and comparative perspectives. Cambridge: Cambridge University Press. p 3-23.

Kay RF, Plavcan JM, Glander KE, Wright PC. 1988. Sexual selection and canine dimorphism in New World monkeys. Am J Phys Anthropol 77:385-397.

Kenagy GJ, Trombulak SC. 1986. Size and function of mammalian testes in relation to body size. J Mammal 67:1-22.

Kitchen DM. 2004. Alpha male black howler monkey responses to loud calls: effect of numeric odds, male companion behaviour and reproductive investment. Anim Behav 67:125-139.

Lawrence B. 1933. Howler monkeys of the palliata group. Bull Mus Comp Zool 75:313-354.

Lee S. 1999. Evolution of human sexual dimorphism: using assigned resampling method to estimate sexual dimorphism when individual sex is unknown. Ph.D. dissertation, Ann Arbor: University of Michigan.

Leigh SR, Setchell JM, Charpentier M, Knapp LA, Wickings EJ. 2008. Canine tooth size and fitness in male mandrills (Mandrillus sphinx). J Hum Evol 55:75-85.

Leutenegger W, Cheverud JM. 1985. Sexual dimorphism in primates: the effects of size. In: Jungers WL, editor. Size and scaling in primate biology. New York: Plenum Press. p 33-50.

Lindenfors P. 2002. Sexually antagonistic selection on primate size. J Evol Biol 15:595-607.

Lucas PW, Corlett RT, Duke DA. 1986. Sexual dimorphism of tooth size in anthropoids. Hum Evol 1:23-39.
Mitani JC, Gros-Louis J, Richards AF. 1996. Sexual dimorphism, the operational sex ratio, and the intensity of male competition in polygynous primates. Am Nat 147:966-980.

Moreland RB, Richardson ME, Lamberski N, Long JA. 2001. Characterizing the reproductive physiology of the male southern black howler monkey, Alouatta caraya. J Androl 22:395403.

Muehlenbein MP, Campbell BC, Murchison MA, Phillippi KM. 2002. Morphological and hormonal parameters in two species of macaques: impact of seasonal breeding. Am J Phys Anthropol 117:218-227.

Murie A. 1935. Mammals from Guatemala and British Honduras. University of Michigan Museum of Zoology Miscellaneous Publications 26:5-33.

Neville MK, Glander KE, Braza F, Rylands AB. 1988. The howling monkeys, genus Alouatta. In: Mittermeier RA, Rylands $\mathrm{AB}$, Coimbra-Filho AF, da Fonseca GAB, editors. Ecology and behavior of Neotropical primates, Vol.2. Washington, DC: World Wildlife Fund. p 349-453.

Ostro LET, Silver SC, Koontz FW, Horwich RH, Brockett R. 2001. Shifts in social structure of black howler (Alouatta pigra) groups associated with natural and experimental variation in population density. Int J Primatol 22:733-748.

Pavelka MSM, Chapman CA. 2006. Population structure of black howlers (Alouatta pigra) in southern Belize and responses to Hurricane Iris. In: Estrada A, Garber PA, Pavelka MSM, Luecke LG, editors. New perspectives in the study of Mesoamerican primates: distribution, ecology, and conservation. New York: Springer. p 143-163.

Plavcan JM. 1993. Canine size and shape in male anthropoid primates. Am J Phys Anthropol 92:201-216.

Plavcan JM. 2000. Inferring social behavior from sexual dimorphism in the fossil record. J Hum Evol 39:327-344.

Plavcan JM. 2001. Sexual dimorphism in primate evolution. Yrbk Phys Anthropol 44:25-53.

Plavcan JM. 2004. Sexual selection, measures of sexual selection, and sexual dimorphism in primates. In: Kappeler PM, van Schaik CP, editors. Sexual selection in primates: new and comparative perspectives. Cambridge: Cambridge University Press. p 230-252.

Plavcan JM, Kay RF. 1988. Sexual dimorphism and dental variability in platyrrhines primates. Int J Prim 9:169-178.

Plavcan JM, Ruff CB. 2008. Canine size, shape, and bending strength in primates and carnivores. Am J Phys Anthropol 136:65-84.

Plavcan JM, van Schaik CP. 1992. Intrasexual competition and canine dimorphism in anthropoid primates. Am J Phys Anthropol 87:461-477.

Plavcan JM, van Schaik CP. 1997. Intrasexual competition and body weight dimorphism in anthropoid primates. Am J Phys Anthropol 103:37-68.

Pope BL. 1966. The population characteristics of howler monkeys (Alouatta caraya) in northern Argentina. Am J Phys Anthropol 24:361-370.

Pope TR. 1990. The reproductive consequences of male cooperation in the red howler monkey: paternity exclusion in multimale and single-male troops using genetic markers. Behav Ecol Sociobiol 27:439-446.

Pope TR. 2000. Reproductive success increases with degree of kinship in cooperative coalitions of female red howler monkey (Alouatta seniculus). Behav Ecol Sociobiol 48:253-267.

Ravosa MJ, Ross CF. 1994. Craniodental allometry and heterochrony in two howler monkeys: Alouatta seniculus and A. palliata. Am J Primatol 33:277-299.

Rodríguez-Luna E, Cortés-Ortiz L. 1994. Translocación y seguimiento de un grupo de monos Alouatta palliata liberado en una isla (1988-1994). Neotrop Primates 2:1-5.

Rosales-Meda M, Estrada A, López JE. 2008. Demographic survey of black howler monkey (Alouatta pigra) in the Lachuá Eco-Region in Alta Verapaz. Guatemala. Am J Primatol 70: 231-237.

Schultz AH. 1929. The technique of measuring the outer body of human fetuses and of primates in general. Contrib Embryol 20:213-257. 
Scott NJ, Scott AF, Malmgren LA. 1977. Capturing and marking howler monkeys for field behavioral studies. Primates 17:527-533.

Sekulic R. 1983. Male relationships and infant deaths in red howler monkeys (Alouatta seniculus). Z Tierpsychol 61:185202.

Setchell BP. 1978. The mammalian testis. Ithaca, NY: Cornell University Press.

Short RV. 1979. Sexual selection and its component parts somatic and genital selection, as illustrated by man and the great apes. Adv Study Behav 9:131-158.

Smith JD. 1970. The systematic status of the black howler monkey, Alouatta pigra Lawrence. J Mammal 51:358-369.

Smith RJ. 1999. Statistics of sexual size dimorphism. J Hum Evol 36:423-459.

Swindler DR. 2002. Primate dentition: an introduction to the teeth of non-human primates. Cambridge: Cambridge University Press.

Steinberg ER, Cortés-Ortiz L, Nieves M, Bolzán AD, GarcíaOrduña F, Hermida-Lagunes J, Canales-Espinosa D, Mudry MD. 2008. The karyotype of Alouatta pigra (primates: platyrrhini): mitotic and meiotic analyses. Cytogenet Genome Res 122:103-109.
Thorén S, Lindenfors P, Kappeler PM. 2006. Phylogenetic analyses of dimorphism in primates: evidence for stronger selection on canine size than on body size. Am J Phys Anthropol 130:50-59.

Treves A. 2001. Reproductive consequences of variation in the composition of howler monkey (Alouatta spp.) groups. Behav Ecol Sociobiol 50:61-71.

Van Belle S, Estrada A. 2006. Demographic features of Alouatta pigra populations in extensive and fragmented forests. In: Estrada A, Garber PA, Pavelka MSM, Luecke LG, editors. New perspectives in the study of Mesoamerican primates: distribution, ecology, and conservation. New York: Springer. p 121-142.

Van Belle S, Estrada A, Strier KB. 2008. Social relationships among male Alouatta pigra. Int J Primatol 29:1481-1498.

Van Belle S, Estrada A, Ziegler TE, Strier KB. 2009. Sexual behavior across ovarian cycles in wild black howler monkeys (Alouatta pigra): male mate guarding and female mate choice. Am J Primatol 71:153-164.

Wang E, Milton K. 2003. Intragroup social relationships of male Alouatta palliata on Barro Colorado Island, Republic of Panama. Int J Primatol 24:1227-1243. 